\title{
Complex of Technology for Processing Heavier Cut of Pyrolysis Gas Oil
}

\section{Authors}

D.V Stalmakh ${ }^{1}$,

Y.A Bulauka ${ }^{1}$,

S.F Yakubouski ${ }^{1}$,

E.A Shulha ${ }^{2}$

Publisher: European Association of Geoscientists \& Engineers

Source: Conference Proceedings, Tyumen 2021, Mar 2021, Volume 2021, p.1 - 5

DOI: https://doi.org/10.3997/2214$\underline{4609.202150056}$

\section{Summary}

In order to improve the profitability of pyrolysis plants organized complex of technology for processing heavier cut of pyrolysis gas oil (PGO) of hydrocarbon raw materials. A complex includes the process of distillation for PGO into strait fractions; fraction boiling up to $230^{\circ}$ could be used to produce plasticizer for concrete mixture obtained by condensation of naphthalene sulfonic acids from PGO and formaldehyde. Optimal parameters for the 
synthesis of plasticizer from PGO have been developed; the best mobility of concrete mixture is obtained from synthesis of plasticizer by the involvement of $\mathrm{C} 10+$ alkylbenzenes with a volumetric ratio of components for sulfonation: PGO:C10+ alkylbenzenes: H2SO4, respectively 10:5:12 respectively. To prevent intensive polymerization during the synthesis of the plasticizer, recommended to heat up slowly to the temperature of reaction and with a deviation, not more than $5^{\circ}$. Residual fractions of PGO of hydrocarbon raw materials (boiling above $230^{\circ}$ ) are characterized by a set of sufficient properties for their use as raw materials for coking. An atomic force microscope analysis of the microstructure of petroleum coke from the residual fraction of PGO established the possibility of elongated anisotropic inclusions specified for petroleum needle coke.

https://www.earthdoc.org/content/papers/10.3997/2214 -4609.202150056\#abstract content 